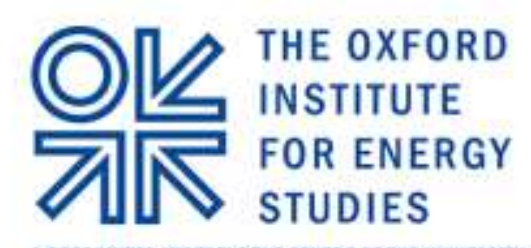

A RECOGMIZED NDEPESOENT CERTRE OF THE UNIVERSITY OF OXFORD

UNIVERSITY OF
OXFORD

February 2019

\title{
Auctions for allocation of offshore wind contracts for difference in the UK
}

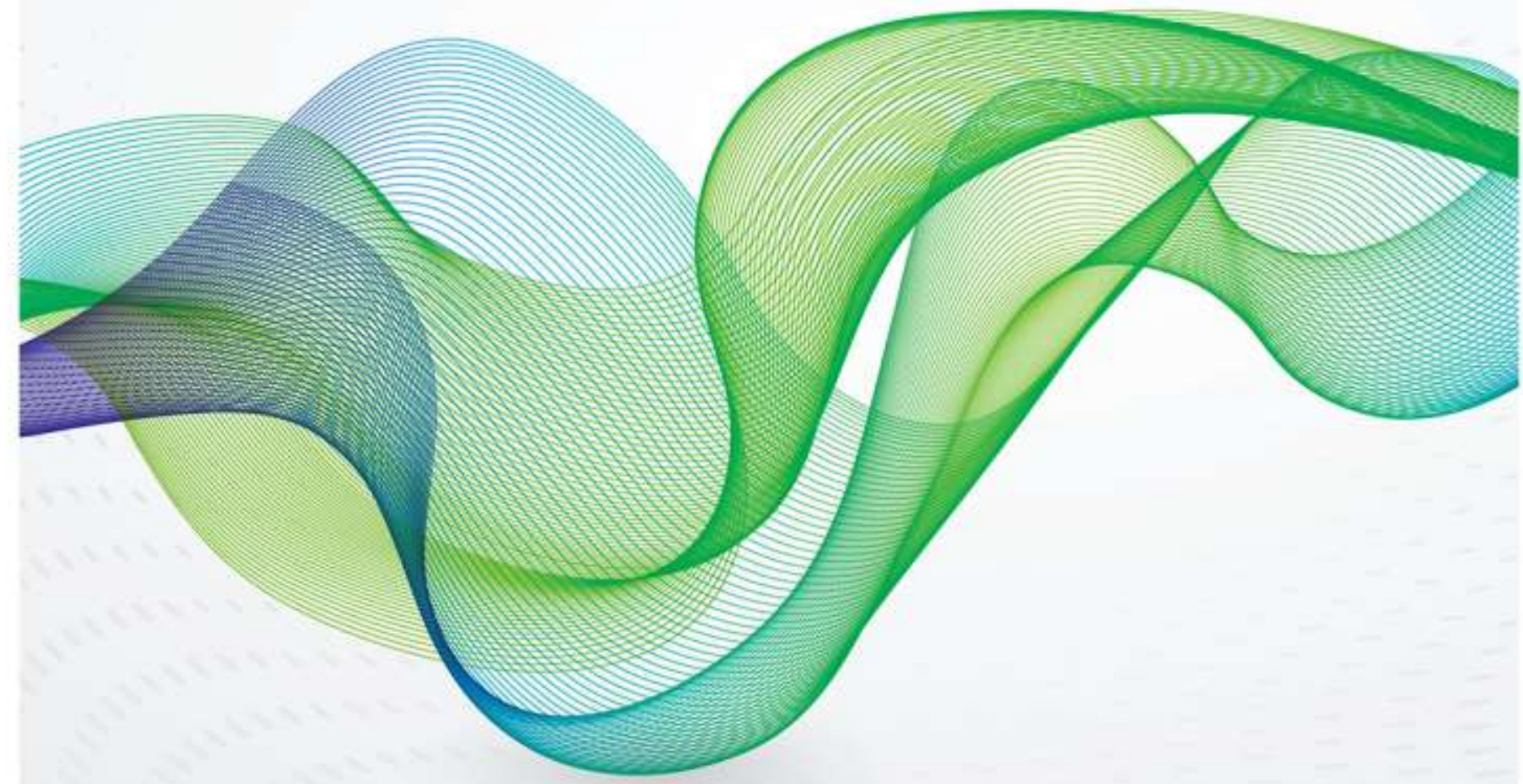



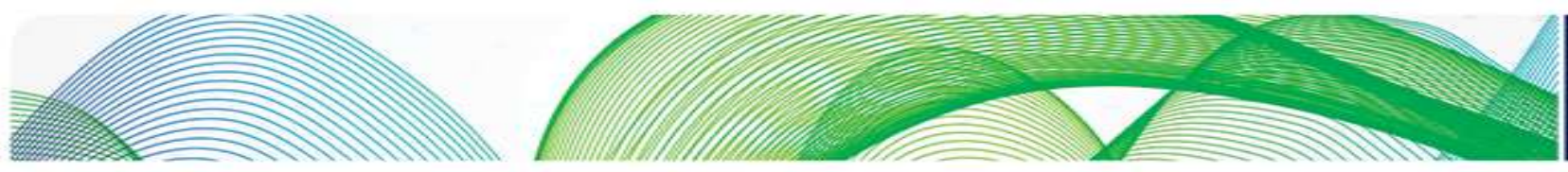

The contents of this paper are the authors' sole responsibility. They do not necessarily represent the views of the Oxford Institute for Energy Studies or any of its members.

Copyright @ 2019

\section{Oxford Institute for Energy Studies}

(Registered Charity, No. 286084)

This publication may be reproduced in part for educational or non-profit purposes without special permission from the copyright holder, provided acknowledgment of the source is made. No use of this publication may be made for resale or for any other commercial purpose whatsoever without prior permission in writing from the Oxford Institute for Energy Studies.

ISBN 978-1-78467-129-7

DOI: https://doi.org/10.26889/9781784671297 


\title{
Auctions for allocation of offshore wind contracts for difference in the UK
}

\author{
Marijke Welisch \\ Senior researcher, Energy Economics Group, TU Wien, Austria \\ Rahmatallah Poudineh \\ Lead Senior Research Fellow, Oxford Institute for Energy Studies, Oxford, UK
}

\begin{abstract}
The contract for difference (CfD) auctions are the cornerstone of the UK electricity sector's decarbonization policy and were introduced as part of the Electricity Market Reform in 2013. The CfD auctions appear to have been successful in achieving low bids for low-carbon technologies, especially offshore wind power. However, the design of the auction increases the probability of speculative bidding, while the one-shot nature of the auction prevents bidders from learning and from utilizing information efficiently. We show that implementing a stringent non-delivery penalty to induce truth telling can improve deployment rate without increasing support costs. Moreover, by holding regularly scheduled (annual, for example) auctions, information on technology cost decreases can be better incorporated into the bids, lowering investor uncertainty and thus having a positive effect on support costs.
\end{abstract}

Keywords: Renewable Energy Auctions, Contract for Difference, Offshore wind, Electricity Market Reform, Real Options Analysis, Auction Theory, Agent-based Modelling 

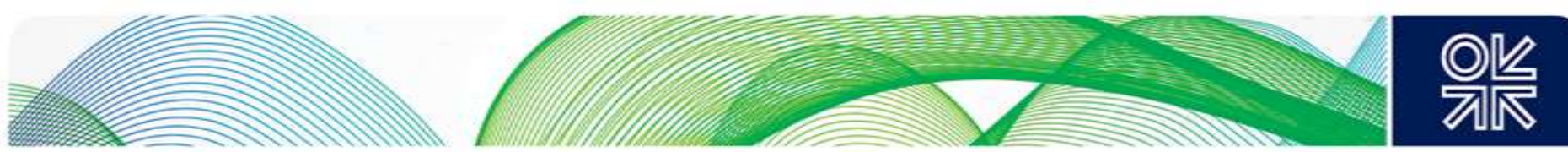

\section{Contents}

Abstract.

ii

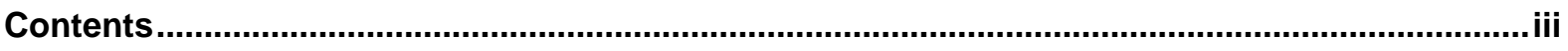

Figures ......................................................................................................................................... iii

1. Introduction ...................................................................................................................................

2. Understanding the UK CfD auctions for pot II (less mature) technologies ...............................2

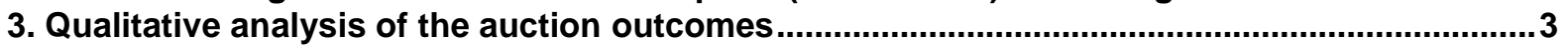

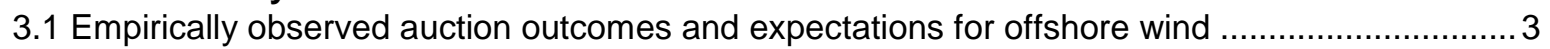

3.2 The auction outcome in the light of literature: a qualitative assessment ................................. 5

3.3 The UK auction outcomes in the light of real options analysis ....................................... 6

4. Quantitative (model-based) assessment of the auction outcomes .......................................... 7

4.1 Methodology: agent-based simulation of a (counterfactual) CfD auction ................................ 8

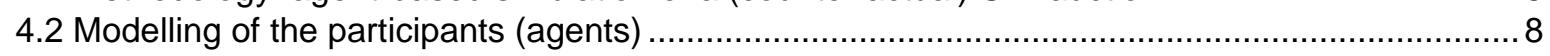

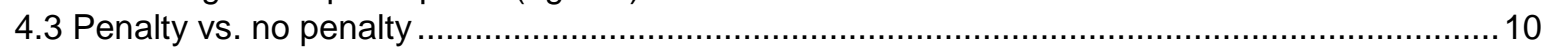

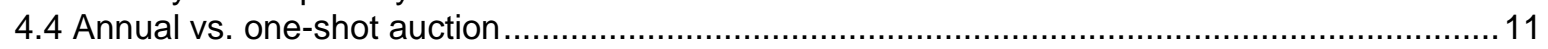

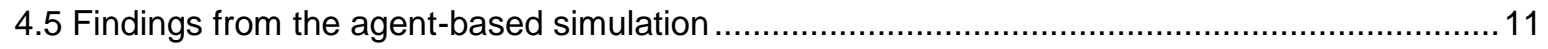

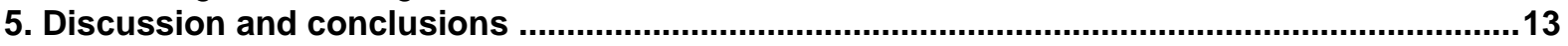

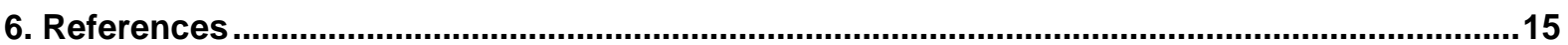

\section{Figures and Tables}

Figure 1: UK CfD Pot II (non-mature technologies) outcomes of the 2014 and 2017 auction rounds ...4 Figure 2: Simplified decision process in the CfD auction participation as according to real options analysis

Figure 3: Simulation of the given auction scheme with and without a penalty (a penalty inducing truthful bidding) and the empirical auction outcomes as comparison

Figure 4: Simulation of the given scheme (assuming a functioning penalty and truthful bidding) on an annual vs. a one-shot basis

Table 1: Modelling input parameters for the agent-based model replication of the UK CfD pot II auctions

Table 2: Changed modelling input parameters for the variations of the CfD auction scheme (with a penalty/annual auctions) 

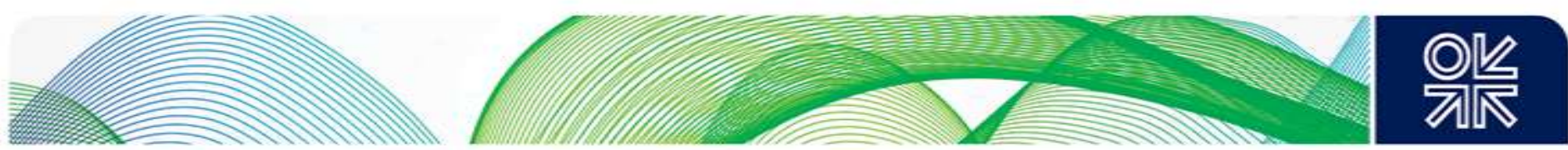

\section{Introduction}

The UK Contract for Difference (CfD) auction scheme, aimed at supporting renewable energy, is an interesting research subject. The low bid prices observed for offshore wind support have gained significant attention from the media. For allocation of CfD contracts, offshore wind was classified as a less-established technology, and we can already resort to two auction rounds for comparison (from 2014 and 2017). The design of the auction was left largely unchanged between these rounds and thus provides a short time series ideal for qualitative and quantitative assessment of the outcome data. Although a range of technologies were eligible in the less-established technology category, around 95 per cent of cleared projects in this pot are offshore wind. We therefore place our focus on this technology in particular. In the second auction round (2017), unexpectedly low price levels for offshore wind have been observed (£57.5/MWh - almost half the price realized in the first round). Costs of offshore wind have been on a descending cost trajectory, but looking at international technology cost reports (such as IRENA (2018)) there is insufficient evidence for such a steep decline.

These extremely low bid prices for offshore wind have raised several questions. Are the support levels high enough to construct viable offshore wind projects? Does the low clearing price reflect a decline in technology cost or an increase in efficiency across the supply chain, or are there alternative explanations for such low prices? In any case, it remains to be seen whether the planned capacity will actually be built and whether the UK will be able to fulfil its targets in renewables deployment. This paper aims to contribute to the discussion by analysing the CfD scheme and the recently achieved auction results in the UK from both a qualitative and a quantitative angle, to gain some perspective and provide the speculations raised with some substantiated background.

A possible explanation for the observed auction outcome is that a non-stringent penalty for failure to deliver the project, along with a long lead time, turns an awarded CfD auction into a kind of 'real option' for developers. Specifically, developers might expect technology costs to drop further over the next few years, such that these projects become profitable. If bidders' calculations turn out to be wrong, they face no stringent penalty for non-delivery in the auctions (a similar research question was assessed beforehand in Welisch (2018)). At the same time, the scheme's one-shot auction design has a lot of inherent uncertainty towards both the capacity awarded and the competition levels in the respective delivery years (points in time at which their project should go online). For the first round, executed in 2014, planning ahead for five different delivery years came with a lot of uncertainty concerning technology cost developments, especially for later years.

The outline of this research paper is as follows. Section 2 discusses the CfD contract allocation process and auction design. The development of the different auction outcomes - in particular the participation levels, bid prices, and timing of projects - are analysed in section 3.1. The empirical outcomes of the past two auction rounds are first evaluated using findings from financing literature (3.2) and then in the light of real options analysis (3.3). This empirical analysis provides first insights into the overall efficiency, benefits, and potential pitfalls of the scheme. Then, in section 4, an agent-based model, previously developed to assess the CfD auction for pot I technologies in Welisch (2018), is used to simulate the CfD auctions, and variations of it, to understand the bidding process and the determinants of the auction outcomes. The findings from the qualitative and quantitative analysis are taken into account to provide an interpretation of the empirical auction outcomes. We also show variations of the scheme aimed at improving its take-up and also its price-finding mechanism and deployment rate ${ }^{1}$ (section 4.5). All results are discussed in section 5, to give an outlook on further developments of offshore wind support in the UK.

${ }^{1}$ So far, one of the awarded project developers of the second pot II technology CfD auction has failed to sign a contract, potentially due to 'aggressive' bidding ('CfD2 project misses cut: Redruth energy-from-waste site fails to sign contract', renews.Biz, 9 October 2017. http://renews.biz/108762/cfd2-project-misses-cut/). 

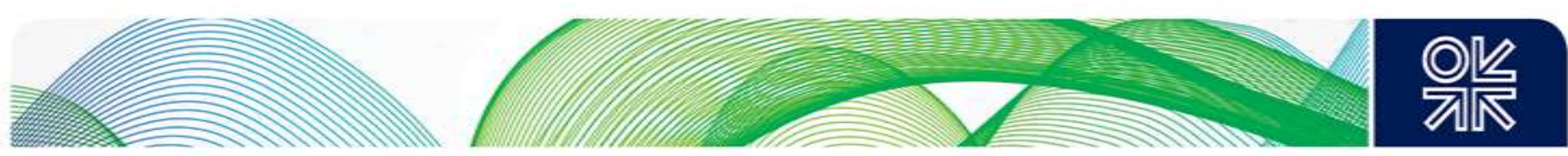

\section{Understanding the UK CfD auctions for pot II (less mature) technologies}

Contracts for Difference are the UK's main policy mechanism to incentivize investment in low-carbon technologies; they were introduced as part of the 2013 Electricity Market Reform. A CfD is a private law bilateral contract between low-carbon generators and the Low Carbon Contract Company (LCCC), a government established company. The contract offers generators a fixed price over (typically) a 15year period by paying them the difference between the CfD's strike price and a market reference price. If the market price is above the CfD price, generators need to pay the difference to the LCCC, and this is then passed on to consumers through their electricity suppliers. Since the introduction of the scheme, around 47 contracts have been awarded, most of them through auctions (NAO, 2017).

Initially, the budget for CfD contracts was set on the basis of two technology categories in two pots: pot I included established technologies (such as onshore wind and solar PV) while pot II comprised lessestablished technologies. The allowed participants in pot II are a variety of renewable technologies: advanced conversion technology (ACT), anaerobic digestion, dedicated biomass with Combined Heat and Power (CHP), geothermal, tidal stream, and wave. Since the end of 2015, the government has excluded onshore wind and solar as eligible technologies for subsequent auctions ${ }^{2}$ and thus the majority of the budget allocated went to less-established technologies in the last auction (Lexology, 2016).

The allocation process for CfD contracts is as follows: National Grid (NG), the delivery body for the Electricity Market Reform, invites applications for the available budget in the pot. Before being able to send applications, bidders have to fulfil a certain number of criteria. A variety of pre-qualification criteria are necessary, including the need for all spatial planning requirements to be met and permits issued. Bidders also have to hold a grid connection agreement. Furthermore, the project must be shown to not be in receipt of funds from other renewable energy source (RES) policies. If the installed capacity is above $300 \mathrm{MW}$, a 'supply chain plan' which details how the project will promote competition, innovation, and skills in the supply chain must be submitted and approved (see Fitch-Roy and Woodman (2016) for more details).

Developers' bids include information about technology type, their price, capacity, and the delivery year of the project. NG ranks all projects on the basis of their strike price, irrespective of the year for which they bid into. If the applications result in a budget breach in any year, NG will hold an auction to allocate contracts. The auction stops if a project's costs exceed the budget cap when it is added to the cost of already awarded projects. Also, if the budget is not breached but the maximum capacity set for some of the fuelled technologies (maxima technology) is exceeded, there would an auction for maxima technology only. The bids in the CfD auction are capped upwards by technology-specific ceiling prices known as 'administrative strike prices'. These ceiling prices are aligned to the previous support levels given by the Renewables Obligation (DECC, 2014). In the event that applications do not lead to a budget breach and/or capacity breach, the contracts will be awarded in a non-competitive fashion on the basis of an administratively set price. Successful applications then sign a contract with the LCCC. If a developer is unable to fulfil its contract, it will be subject to a non-delivery disincentive mechanism. This means that it would not be able to participate in the next CfD auction if it occurs in the following two years (NAO, 2017). This penalty, however, is considered to be non-stringent.

The auction for allocation of the contract for difference is a multi-unit, ${ }^{3}$ sealed-bid ${ }^{4}$ uniform price (payas-cleared) auction format. Uniform pricing means that all successful bidders in the same delivery year

\footnotetext{
2 This decision may change and these technologies might be allowed to participate in the auction again.

3 'Multi-unit' means that bidders submit bids for multiple units of a good: in this auction setting, the 'good' is capacity - in other words, they submit a bid per MWh for multiple units of MW of a plant they are planning to construct. The CfD awarded thereafter is, however, for the electricity generated (per MWh actually offered at the market).

${ }^{4}$ A sealed-bid auction, in comparison to an open-bid format, is an auction where all bids are collected at the same time (or up to a certain point in time); they are then ranked in a particular order (in this case: lowest to highest). Bidders only learn their
} 

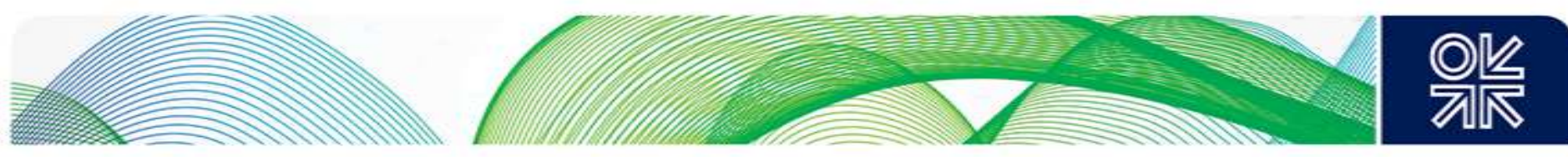

receive the same remuneration, which is determined by the highest awarded bid (strike price). This bid thus determines the remuneration that all bidders in this technology category and delivery year will receive for each unit of electricity generated.

In the $\mathrm{CfD}$ auction scheme, one round takes place, inviting participants to place their bid into a selection of delivery years. So far, two auctions have been held for less mature technologies - one in 2014 and one in 2017 - offering the option to bid into five (2014) and two (2017) delivery years respectively. The CfD auction in the UK has certain features that create some degree of uncertainty for both prospective investors and power system planning. First it does not follow a fixed schedule, so developers cannot plan in advance with the anticipation of an upcoming auction. Second, auctioned volumes are determined by an annual budget, not by a particular amount of capacity: the budgets are capped yearby-year such that a winning bid must be comprised in the budget cap for the respective delivery year. This means it is hard to predetermine which amount of capacity will come online at what point in time, compared with the case where a fixed schedule exists and a fixed amount of generation capacity is tendered. Furthermore, the contract for difference entitles project developers to the strike price, but generators need to sell their resources in the electricity market (in other words, the CfD requires resources to participate in the market). This secures a certain income for the generator, but does not allow that entity to collect all revenues from the electricity market (particularly the case for independent generators). This is because lenders require project developers who seek project finance to secure a suitable Power Purchase Agreement (PPA). In the UK there is a market for renewable PPA contracts, but offtakers apply a discount when offering a PPA to CfD contract holders.

\section{Qualitative analysis of the auction outcomes}

\subsection{Empirically observed auction outcomes and expectations for offshore wind}

Offshore wind made up the main share (over 95 per cent) of the awarded technologies in the past two auction rounds for non-mature technologies. Besides this, advanced conversion technologies also placed some successful bids in the last two rounds. All other technologies were not awarded. It is not known whether they actually participated in the auctions or submitted invalid bids. Furthermore, only a few large projects were awarded, while for some delivery years (such as 2019/20 and 2020/21), no offshore wind bids were placed at all in the first round (2014). The exact reason for the lack of bids in the aforementioned delivery years during the first round is unclear. It might be because the project sizes submitted were still relatively small, as bidders first wanted to become accustomed to the new form of renewable support policy (namely CfD auctions). It could also be due to the fact that competing subsidy schemes existed at the same time (in other words, the Renewables Obligation under which more than $5 \mathrm{GW}$ of offshore wind were accredited in 2017/18, see, for example, Mahoney (2018)). One could also argue that the CfD scheme is quite complex (see, among others, Fitch-Roy and Woodman (2016)) and contains several uncertainties for investors (such as an unfixed schedule, budget cap, and difficulty of finding a suitable PPA offtaker). While the Renewables Obligation will cease to exist in 2019, the CfD auctions will continue to provide support to offshore wind and other 'non-mature' technologies until they reach market maturity.

From the perspective of prices, CfD auctions have been largely effective in lowering the cleared price for offshore wind between the first and second rounds. In Figure 1, auctioned capacities (translated from the budget using the budget impact equation provided by the Department for Business, Energy \& Industrial Strategy (BEIS), making use of the strike prices achieved) are shown, together with the share

competitors' bid prices after the auction has ended, that is, they do not have a chance to adapt their bids according to their competitors, as is the case in an open-bid auction. The differentiation is also often made into static and dynamic auction formats. 

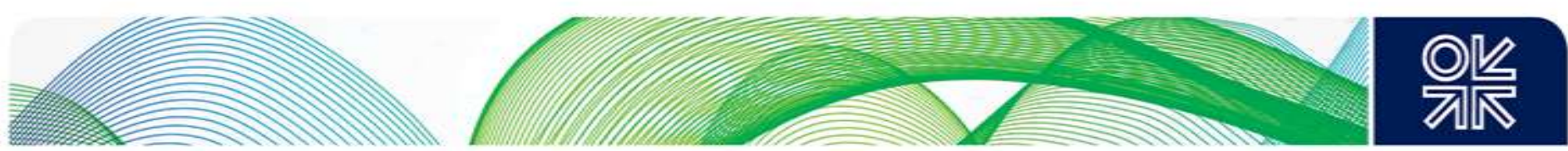

of the actually awarded capacities and the strike price. Overall, the strike price exhibited a dramatic decrease (especially in the second auction round, which took place in 2017). Namely it went down to $£ 57 / \mathrm{MWh}$ for the delivery year 2022/23 - less than half the price of projects which are currently under construction. According to Evans (2018), the definition of subsidy-free renewables favoured by the UK Treasury requires a subsidy-free scheme to have a cost below the market price - currently around $£ 50 / \mathrm{MWh}$ in the UK - from day one. The most recent auction outcomes therefore place offshore wind very close to the subsidy-free category.

Figure 1: UK CfD Pot II (non-mature technologies) outcomes of the 2014 and 2017 auction rounds

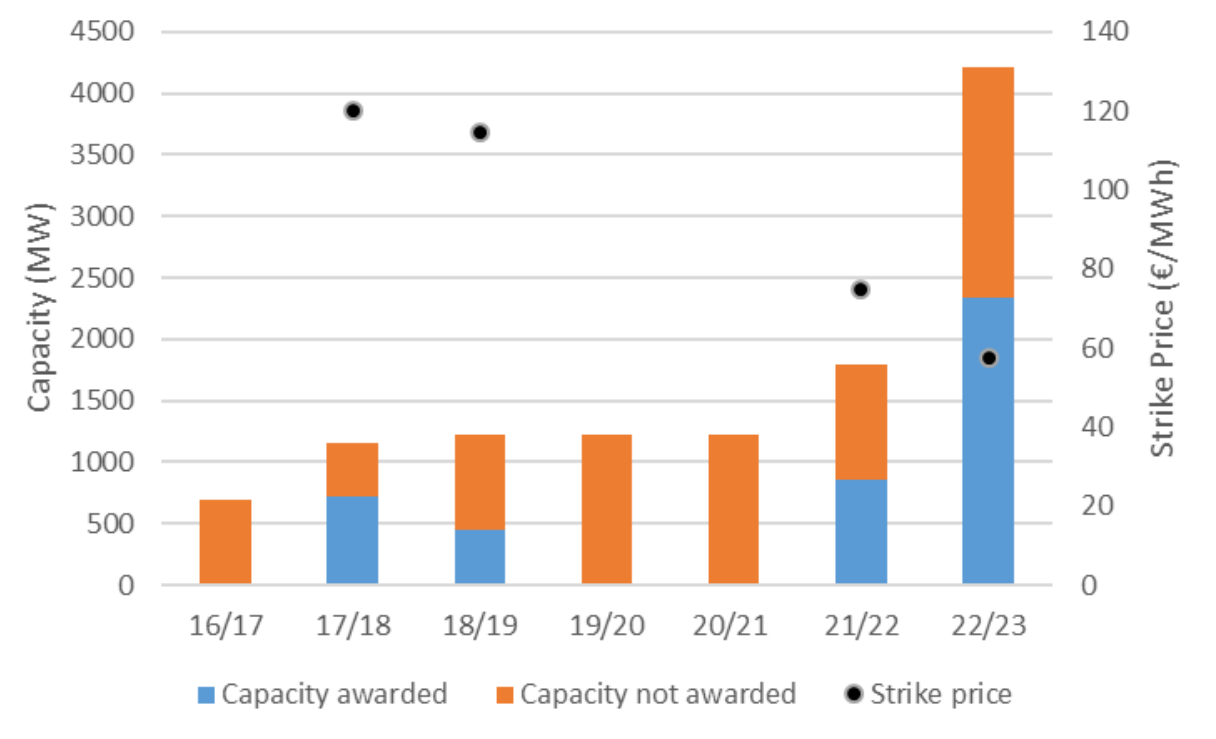

Source: BEIS, authors

Similar trends are also being observed in other European jurisdictions. Auction-based support for renewable energy introduced by the European Commission in 2014 foresees a gradual implementation of 'competitive bidding processes' for allocating public support (European Commission, 2014). In most European jurisdictions, the support is in the form of a premium on electricity market prices, and developers bid for the premium. This means that if market maturity of a technology is reached (given a functioning scheme), zero-subsidy bids (meaning also bids in line with electricity market prices) would be placed in these bidding processes, showing that additional support for the respective technology is no longer necessary. Zero-subsidy bids have already been placed in some European countries such as Germany (to be delivered in 2024 and 2025) and the Netherlands (to be delivered in 2022); however (as explained in the following), this does not necessarily include hidden subsidies (Evans, 2018).

In Germany, for instance, Orsted and EnBW submitted bids to build an offshore wind farm in 2024/25 without any subsidy (Aurora, 2018). The developer expects that by the delivery year, large-scale turbines of the order $15 \mathrm{MW}$ would become available and thus create significant production and O\&M efficiency. In a similar manner, Vattenfall and Statoil have made subsidy-free bids in the recent Dutch auction for offshore wind.

Although the trajectory of bid prices observed shows a common trend towards subsidy-free renewables, there are some crucial differences between the UK CfD model and the European premium scheme for supporting offshore wind. First of all, in the UK, bidders bid for a contract for difference, in other words, in every settlement hour, they receive a specific amount, not more, not less. However, in the premium model, in the case of high hourly electricity spot prices, generators can keep the surplus. Second, according to Evans (2018), if the government provides the grid connection as a de-risking measure, or other services such as site location scoping, this contains an additional hidden subsidy for the renewables project. While in the UK generators have to pay for all these features, in Germany, the 

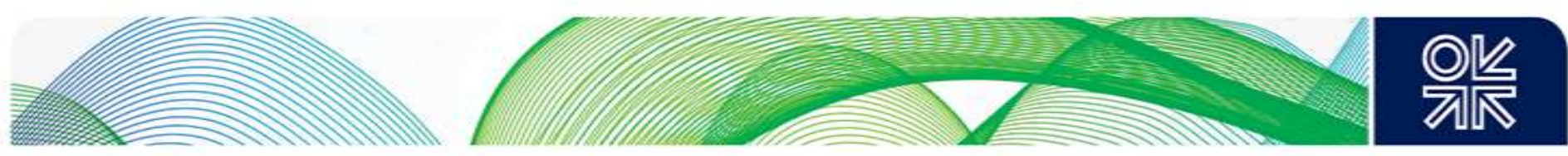

Netherlands, and Denmark grid connection and other parts of the project are guaranteed by the state (Evans, 2018) - thus making the outcomes of auctions not directly comparable. Specifically, this means that in order to take prices in the other countries into account, the investment costs have to be reduced by the respective part that is guaranteed by the state. As grid connection is concerned, this is quite a substantial amount. Lastly, the duration of the support scheme is also important. While in Denmark, Germany, and the Netherlands support is paid for 20 years, in the UK it is only guaranteed for 15 . Therefore, taking into account these additional factors, the UK CfD auction result is one of the lowest and thus raises the question of realization potential - or rather if there is a risk of default.

\subsection{The auction outcome in the light of literature: a qualitative assessment}

An important question concerns the factors which may influence the bidding behaviour and investment decision of investors in a renewable technology such as offshore wind. Such analysis is useful, as it provides an initial interpretation of the auction outcome. The literature refers to a range of key factors such as: uncertainty, flexibility, ability to hedge, expectations concerning the carbon price path, and expectations of technology cost development that affect the investment decision of a project developer.

Martínez-Ceseña and Mutale (2012) and Martínez-Ceseña and Mutale (2011) argue that flexibility concerning the timing and scope of a renewables project can help investors make the most profitable choices. As offshore wind bidders in the UK CfD auctions can bid into different delivery years and, furthermore, phase their projects, the CfD scheme offers a lot of flexibility that allows investors to bid very optimistically.

Uncertainty also plays a key role in the decision making of investors. It can affect not only the specifications of a project but also its timing. Heggedal et al. (2011) for instance, confirm that the value of waiting is higher under shifts in political regimes. Furthermore Boomsma et al. (2012) state that uncertainty with respect to a change of support scheme creates an incentive to defer investment - as waiting longer increases the probability of lower technology costs and increases the level of information on the side of the bidder. The authors also investigate how the behaviour of investors is affected by regulatory uncertainty: an 'option' in their definition refers to the ability of the investor to postpone investment until the economic environment justifies further commitment of funds. This could explain the tendency to phase projects in the offshore wind CfD auctions in order to spread the risk over several years.

Recent literature on financing renewables and renewable energy support shows that underbidding (in other words, submitting bids that lie below the true costs) often takes place in expectation of higher carbon prices (May et al., 2017) especially in places where a generator's remuneration is linked to power prices. The bidders expect increased carbon prices to place an upward pressure on wholesale power market prices. The risk of factoring such expectations into the bid is that if carbon prices and electricity prices do not develop as envisaged, projects could become unviable and would thus not be constructed. In the case of the UK carbon price, this is not crucial, as during the terms of CfD contracts project developers are shielded from the market price. However, CfD contracts are only awarded for 15 years and generators' revenues post CfD are of critical importance. It could be the case that bidders form an expectation about developments in the electricity market price beyond the 15-year horizon and factor that into their bidding.

A recent report by WindEurope (2017) shows the importance of hedging in financing offshore wind projects. The authors find that hedging can impact the capital structure of a project, by creating more debt capacity and enhancing risk adjusted returns. They show that in Europe, offshore (and total) wind investments declined for the first time in 2016 - an expected decline, due to the transition to auctionbased support schemes. Offshore wind has a much higher share of corporate finance compared to onshore. This makes hedging crucial in both the long and the short term. For offshore investments, therefore, increased risks due to fluctuations in income from the electricity market have a strong influence on investment decisions. Having a steady flow of income - even if comparatively low secured by government contracts (CfDs) thus becomes more appealing to these investors. This could 

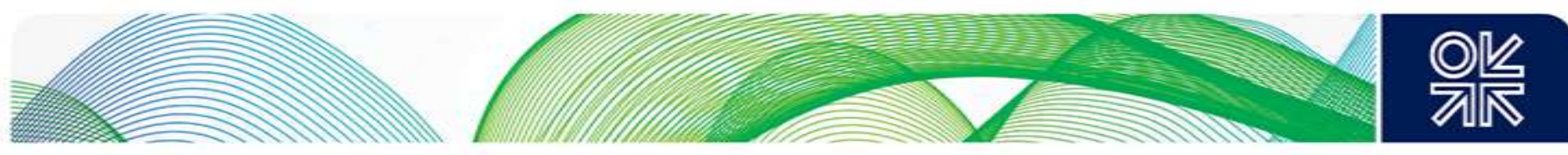

potentially increase the competition in offshore wind auctions and might be among the reasons for the very low levels of support that bidders aimed for in the second round of the CfD auctions in the UK.

Finally, Bowman and Moskowitz (2001) show that companies need to perform both strategic and financial analysis. The financial analysis concerns all known factors (such as costs of seabed lease) whereas the strategic analysis concerns the assessment of uncertainties (such as technology cost developments or developments on the electricity spot market). The strategic part of the investment strategy is crucial and seems to be non-negligible, especially when offshore wind auctions are concerned, due to the large uncertainties when it comes to cost developments for future projects. Other reasoning - such as first-mover advantage and securing important market shares or grid connection for later stages - is also likely to influence bidders, in addition to the expected returns from their currently offered projects. These factors are beyond modelling and, because of their commercial sensitivity, data about them is not often shared by investors or electricity generation companies.

\subsection{The UK auction outcomes in the light of real options analysis}

One conclusion from the above literature analysis is that real options analysis can also deliver some useful insights in the interpretation of the UK CfD auction outcomes. This approach to the capital investment decision provides a different perspective on the valuation of projects, as it captures the value of flexibility as well as strategic value, and provides intuition that may be contrary to popular thinking. Commonly, a real options approach can be summarized as a two stage decision process - first, a company makes a small investment and a few years later, when more information is known, the decision about a large investment is made (Bowman and Moskowitz, 2001).

A company's decision process in the UK CfD auctions has been exemplified in Figure 2, which is an adaptation of the real options assessment made by NERA (2017). What is shown, are the following (simplified) steps of the different investment options (phases $t=0 \ldots 5) .{ }^{5}$ The phases are implemented to represent the bidder's liberty to decide on whether to construct all the capacity at once or, instead, to phase the project and distribute it over more, at maximum three, construction periods. Furthermore, very simplified assumptions are made on the revenues that can be achieved following different developments in the market and in technology costs - and the corresponding decisions made by the investor. As the UK CfD auctions do not foresee any substantial penalty payments for non-delivery, bidders can easily decide if they want to construct their project under the CfD scheme or default, depending on the technology costs in the respective delivery year. To give a very simple, made-up example, we can assume that the sunk costs for a project to qualify are £5 million. So the decision to participate in the auction leads to $-£ 5$ million for the investor in phase 0 . The investor has a certain estimate concerning the development of technology costs. If they fall, her project will be profitable (let's say $£ 30$ million). If technology costs stay high, the project would be non-profitable (for example $-£ 15$ million). In the case where technology costs are low, the investor constructs the project. When the project is not profitable, the bidder can default and minimize the loss to the sunk costs from phase 0 , or construct only one phase at a loss and then wait for the cost developments before potentially constructing the second phase, or deciding against it.

Overall, one can see that the scheme gives investors a variety of options and thus leads to substantial uncertainty concerning the actual deployment that will be achieved in the long term.

\footnotetext{
${ }^{5}$ Whereas (NERA, 2017) show how the real option for auction participants is the average between the penalty and the expected loss from constructing a project - in this particular case, no penalty exists, so the investor only accounts for the sunk costs from prequalifying, which are comparatively low.
} 

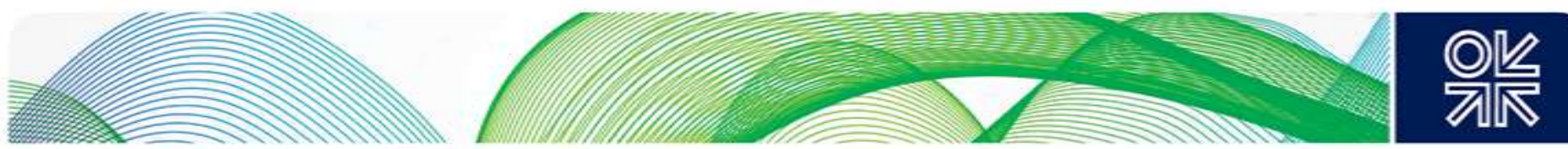

Figure 2: Simplified decision process in the CfD auction participation as according to real options analysis
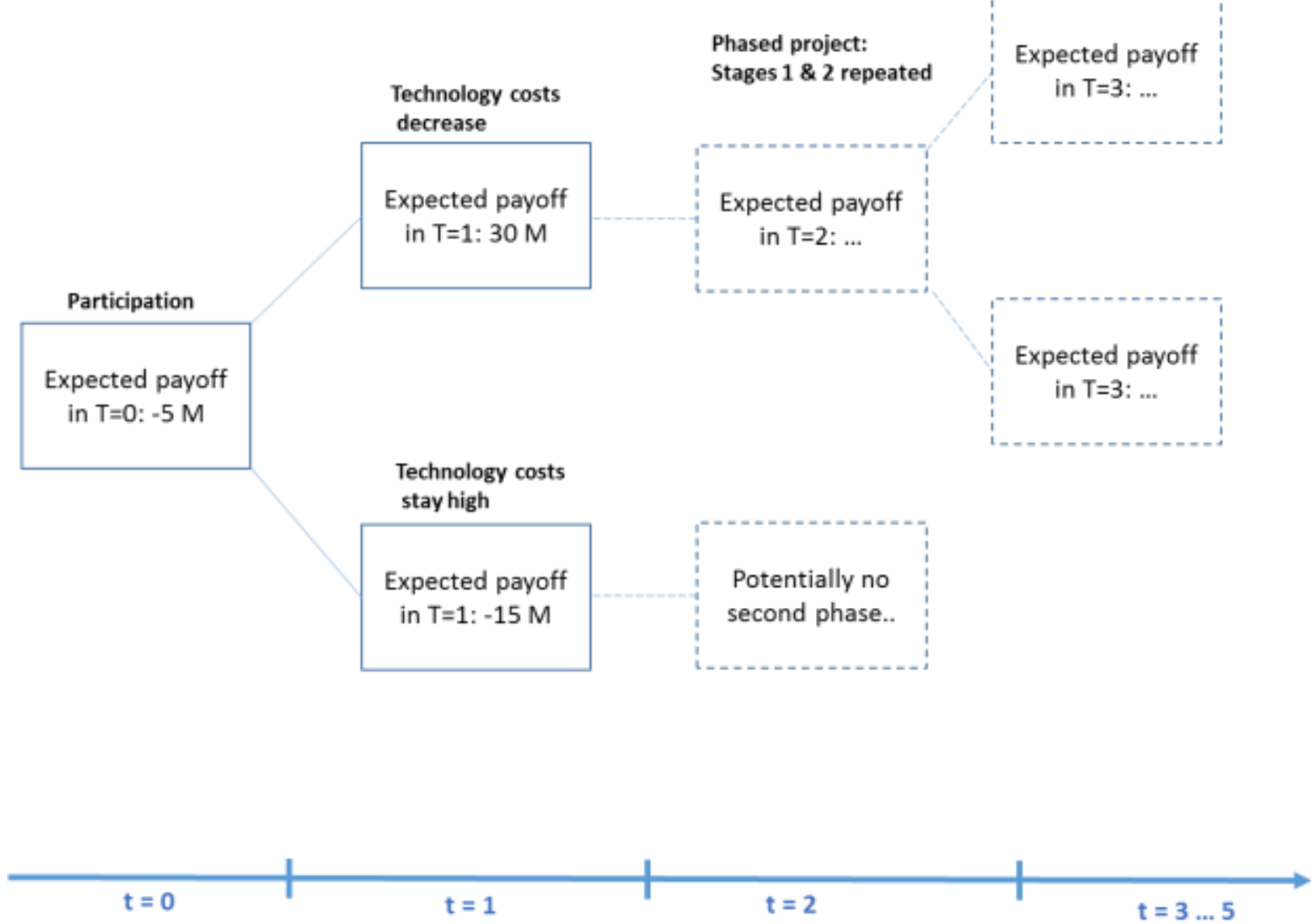

Source: authors

\section{Quantitative (model-based) assessment of the auction outcomes}

The previous qualitative analysis provides interesting ideas and potential first explanations of the empirically observed auction outcomes. To see if these explanations can be quantitatively validated, we model two variations of the auction scheme, showing how the auction participants' behaviour is influenced by different auction design parameters. There is some degree of uncertainty as to whether the UK CfD auction scheme will actually lead to projects being constructed under the very low support levels that were achieved in the second auction. We will therefore assess two variations of the scheme with an agent-based model. First, we look at how investor rationale changes when bidders account for a penalty in their bidding behaviour. Second, in order to look at uncertainty towards cost development, learning effects, and investor certainty, we compare the current one-shot auction outcome with a multiannual scheme.

For the modelling part, we build on work already executed in Welisch (2018). We also take into account the weighted average cost of capital (WACC) based on the most recently available technology cost data and on studies on risk perception concerning renewables investments. We look into predicted cost trajectories for technologies and find a range of expected support for cost developments, from which we calculate a reasonable LCOE to be expected for offshore wind in the respective delivery years. 

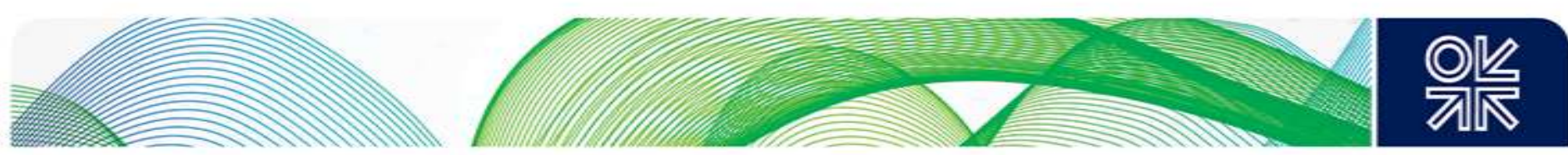

\subsection{Methodology: agent-based simulation of a (counterfactual) CfD auction}

In auction theory, the bid function maps an agent's cost for realizing the project (or valuation of a good) to a bid price. In uniform pricing, agents can receive $b$, the highest accepted, or lowest not awarded, bid, or 0 depending on the auction's outcome and try to maximize their profit (Krishna, 2010) The bid function is derived from auction theory. Several studies have shown that revealing one's true cost in a multi-unit auction with uniform pricing (when each agent only places one bid) or in a second price auction - the single unit equivalent - is a weakly dominant strategy (Milgrom, 2004) $\beta$ is thus the bidding strategy applied:

$$
\beta\left(c_{t}^{i}\right)=c_{t}^{i}
$$

where $c_{t}^{i}$ is the true cost of bidder $i$ in the round $t$. In the simulation, agents thus bid truthfully (their exact costs $c$ ) in every round $t$. According to theory, the outcome of a functioning uniform pricing regime is incentive-compatible (Klemperer, 2004) (However, a different strategy is modelled for the case where agents have an incentive to bid strategically instead of revealing their true costs, which is shown later on. As one auction is held for several delivery years, participants have to make an estimate on the competition in the delivery year they bid into and calculate their strategic bid. The assumptions made for this are outlined in the following sections. To average over stochastic elements of the simulation (Hailu et al., 2011), all results presented are averages of 100 simulation rounds.

The auction design has been simplified: we have used the annually capped budget to calculate an amount of capacity auctioned off in each delivery year. Participants in the UK renewables auctions have to estimate which amount of tendered capacity is represented by the annual budget. Thus, for the model, the same procedure was performed to transform the monetary budget cap into an amount of MW in each delivery year. For this, we used the official valuation formula depicted in the 2014 allocation framework (DECC, 2014). This procedure has already been validated and explained in Welisch (2018). The model was then calibrated for an offshore wind auction with additional ACT bidders, as was empirically observed.

\subsection{Modelling of the participants (agents)}

The depiction of the agents takes into account a variety of cost data and assumptions. As it is difficult to get hold of actual offshore wind cost data or projections that generators make for future investments (due to their commercial sensitivity), we rely largely on publicly available studies such as IRENA (2018) or McKinsey (2018) and interpolate for missing years to receive appropriate cost estimates.

No information was available on the number of total bidders, so we assume that only the actually awarded projects participated in the auction. ${ }^{6}$ The budget cap (maximum volume) was not reached in any of the delivery years. On average $500 \mathrm{MW}$ of projects bid into the first delivery year, with a slight increase in each subsequent year. The auction results were further analysed to approximate the size of the participating projects.

Our main focus lies on offshore wind bidders. To achieve a realistic depiction of the auctions that took place in 2014 and 2017, however, we also model those participating ACT bidders who are able, even though they are only of negligible size, to impact the outcome of the auction. For the ACT bidders, we draw on empirical auction outcome data and interpolate between bidding years whenever no cost estimate is available. For offshore wind bidders, however, more complex and strategic bidding behaviour is depicted. The assumptions taken on the participating bidders are summarized in Table 1:

\footnotetext{
${ }^{6}$ The budget cap was not reached in any of the delivery years. This might be because the last project had submitted a bid with a capacity that exceeds the budget for the delivery years, or because projects did not qualify at all or had submitted bids above the ceiling price ('administrative strike price'). As neither factor would have affected the actual auction outcome, the assumption on participants is valid and the level of competition that is modelled is a realistic depiction of the auctions that took place in 2014 and 2017
} 

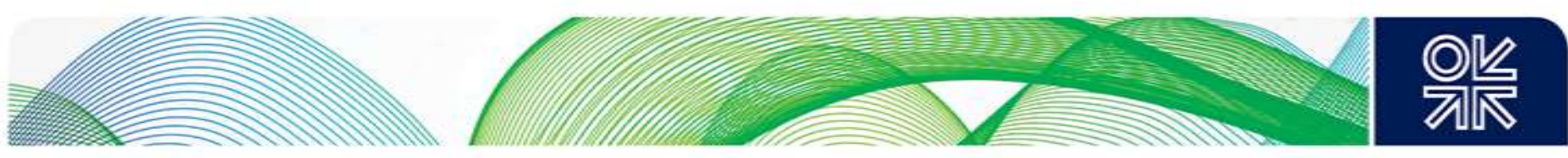

Table 1: Modelling input parameters for the agent-based model replication of the UK CfD pot II auctions Original Scheme

\begin{tabular}{|c|c|c|c|c|c|c|}
\hline & & $\begin{array}{l}\text { Cost range } \\
\text { (p/kWh) } \\
2014 \\
\text { (Delivery } \\
\text { year } \\
2017 / 18 \text { ) }\end{array}$ & $\begin{array}{l}\text { Cost range } \\
\text { (p/kWh) } \\
2017 \\
\text { (Delivery } \\
\text { year } \\
2020 / 21 \text { ) }\end{array}$ & $\begin{array}{l}\text { Size } \\
(\mathrm{MW})\end{array}$ & $\begin{array}{l}\text { Range of } \\
\text { cost } \\
\text { uncertainty }\end{array}$ & Cost degression \\
\hline \multirow{2}{*}{ ACT } & $\begin{array}{l}\text { Risk } \\
\text { loving }\end{array}$ & $9 ; 11.4^{a}$ & $5 ; 7.4$ & $5 ; 25$ & $(-10 / 10 \%)$ & as observed empiricallyc \\
\hline & $\begin{array}{l}\text { Risk } \\
\text { averse }\end{array}$ & $9 ; 11.4$ & $5 ; 7.4$ & $5 ; 25$ & $(-5 / 5 \%)$ & as observed empiricallyc \\
\hline \multirow{2}{*}{$\begin{array}{l}\text { Offshore } \\
\text { Wind }\end{array}$} & $\begin{array}{l}\text { Risk } \\
\text { loving }\end{array}$ & $8.4 ; 13.8$ & $6.6 ; 11^{a}$ & $\begin{array}{l}300 ; \\
1000\end{array}$ & $(-10 / 10 \%)$ & $4 \%$ annually; $23 \%$ last round ${ }^{d}$ \\
\hline & $\begin{array}{l}\text { Risk } \\
\text { averse }\end{array}$ & $8.4 ; 13.8$ & $7.4 ; 12.3^{b}$ & $\begin{array}{l}300 ; \\
1000\end{array}$ & $(-5 / 5 \%)$ & $4 \%$ annually; $23 \%$ last round \\
\hline
\end{tabular}

Note: ${ }^{a}$ Risk-loving bidders assume a discount period of 20 years (later up to 30, for the 2017 bidding round), as they expect positive developments of the market price; ${ }^{b}$ Risk-averse bidders want to write off their project in the timely constraints of the support scheme, namely discount 15 years; ${ }^{c}$ Degression as observed empirically, interpolated for missing years; ${ }^{d}$ Degression in first auction based on cost data by (McKinsey, 2018), in second auction based on empirically observed extreme decline and predictions by (IRENA, 2018).

Source: authors

To depict a realistic range of participants, we let them differ in their respective cost distribution. Longterm bidding behaviour is also differentiated, as we assume a certain preference towards later bidding years for some bidders, inferring that not all bidders have a sufficiently established value chain to deliver projects within a short-term construction period. Assumptions on technology cost degression influence bidders' valuations of future delivery years. In the base modelling case (repeating the CfD auctions with all parameters available in the simulation) this is implemented as five (two) delivery years with a yearby-year cost degression, but without learning from the outcome of previous delivery years.

We also assume that bidders differ in terms of risk aversion. We have one bidder type that takes more risks and another that is risk averse. The risk-loving bidder type has positive expectations towards the development of electricity market prices and thus discounts her investment over 20 years, assuming that after 15 years of receiving the $\mathrm{CfD}$, revenues from the market will be positive and the project beneficial. The risk-averse type is less optimistic and wants to write off the project before it falls out of the scheme, in other words, after 15 years of project lifetime. For the latest bidding round, for those projects that are phased way into 2023, we can even assume that some of the risk-loving bidders expect a project lifetime of 30 years and can thus make even more optimistic estimates towards their necessary LCOE. Overall, we use several official cost and technology data sources to calculate the expected 

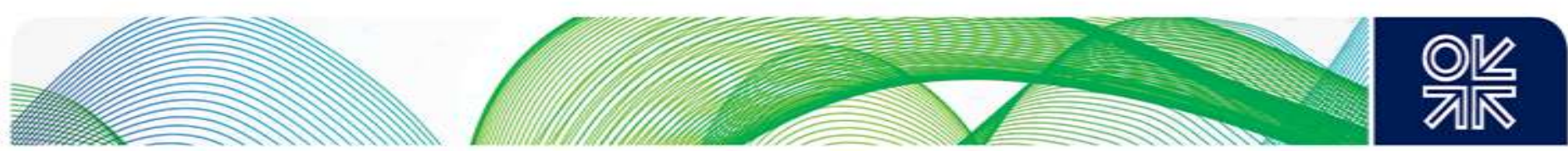

LCOE for the respective types: IRENA (2018), McKinsey (2018), and TU Wien's Green-X Model Input data.7

Table 2 depicts which input parameters were changed for the agents in comparison to Table 1, for the following varied simulations of the CfD auctions. In the following, the procedure as well as the underlying theory will be explained in more detail.

Table 2: Changed modelling input parameters for the variations of the CfD auction scheme (with a penalty/annual auctions)

\begin{tabular}{|l|l|}
\hline \multicolumn{1}{|c|}{ Scheme with penalty } & \multicolumn{1}{c|}{ Annual auctions } \\
\hline $\begin{array}{l}\text { No range of uncertainty for any technology; bid } \\
\text { submission of true costs only }\end{array}$ & $\begin{array}{l}\text { Cost degression changes (adaptation to } \\
\text { previous rounds and recently available cost } \\
\text { data (McKinsey, 2018)): } 6 \% \text { annually }\end{array}$ \\
\hline
\end{tabular}

Source: authors

\subsection{Penalty vs. no penalty}

In the UK CfD auction, underbidding due to a lack of penalties or pre-qualification criteria is probable. As shown above, bidding behaviour changes, depending on whether the bidder factors in a penalty or not. In the base case (a repeat of the CfD scheme), the auction scheme does not include a penalty (or a financial pre-qualification that could be lost). Therefore, bidders can without consequence reject an awarded bid if they experience winners' curse. ${ }^{8}$ The base case bidders are thus modelled with a different bidding function because they are uncertain about their true costs (due to the lack of penalty) so they might bid below (or above) them. This happens for two reasons. First, to increase their award probability or the awarded bid price and thus their expected revenue. Second, because they are not induced to truth telling/calculating their exact costs, as the auction scheme does not rigorously follow up on a potential default.

In the model, this is implemented as follows: agents receive a signal on where their costs lie (in other words, the model assigns to the participant the cost from their respective distribution). This signal lies in a cost range, taking into account uncertainty concerning the costs of a project. This uncertainty increases the likelihood that bidders submit a bid below (or above) their true costs. The bidder receives a signal $x$ with an uncertainty factor $\delta$, which determines its bid price $y$ :

$$
y=x+\delta
$$

where $\delta \in[-\varepsilon, \varepsilon]$

The bidding function resulting is:

$$
\beta\left(c_{t}^{i}\right)=x_{t}^{i}-\delta
$$

Where $i$ is the agent and $t$ is the respective delivery year the agent bids into (a point in time). The uncertainty factor $\delta$ is varied, to model different levels of risk aversion among bidders. As the bidder has the option to default, she is able to submit a bid in the lower bound of the range of her signal, even though it might result in a loss. This means that bidders in this particular setting act in a less risk averse manner than those confronted with a cost in the case of defaulting. If the auction outcome is not favourable for the bidder (in other words, it results in a negative profit), she does not accept the bid.

\footnotetext{
${ }^{7}$ Energy Economics Group website, http://www.green-x.at/.

${ }^{8}$ Meaning that they strategically or accidentally underbid and now cannot cover their costs, because the final strike price is too low.
} 

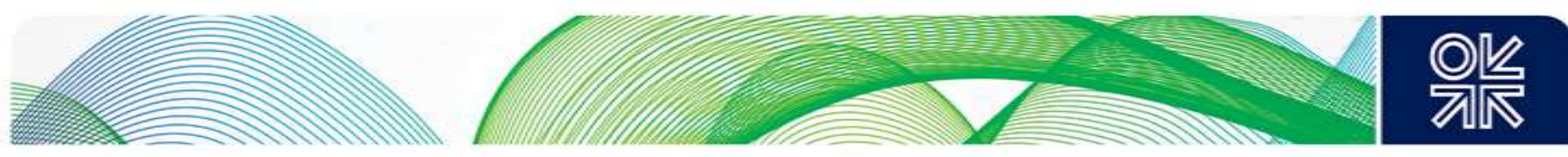

The equations shown are adaptations of Board (2007). The distribution of the uncertainty factor is assumed to be either 5 or 10 per cent above or below the cost signal $[-5 \%, 5 \%],[-10 \%, 10 \%]$, comparable to Welisch (2018).

We also model counterfactual schemes that apply two changes to the auction design, each reducing the uncertainty of bidders. The first variation assumes a penalty in place that forces bidders to submit their true costs, thus making auction participation less of a real options approach. The second variation assumes that annual auctions take place, instead of there being a one-shot auction for several delivery years. This enables bidders to take more recent cost estimates and the competition level of previous rounds into account. It also gives them a better idea on the overall capacity available - potentially attracting more participants. In short, we model a comparison of a) having bidders solely submit their true costs and $b$ ) having bidders participate in rounds for each delivery year and thus being able to bid more precisely. The counterfactual schemes, together with the simulation repeating the actual auctions assuming bidder rationality, will show us if the empirical outcomes are actually counterintuitive.

\subsection{Annual vs. one-shot auction}

Comparing the annual and the one-shot auction in agent-based modelling gives important insights into how a more consistent policy might improve participation rates in the auction and, furthermore, it allows decreases in technology costs to be directly reflected in necessary levels of support.

The one-shot auctions are modelled as two separate model runs, where bidders decide on one (or several) delivery years. As the decision has to be made long term (especially in the 2014 auction round) and no information has been generated from previous auction rounds, these bidders are less informed than those participating in the proposed counterfactual annual auction scheme. To model this, we make use of the empirical auction outcomes as a starting point for the bidders' cost distribution, and interpolate or add additional cost data when necessary. We assume that bidders at an early stage are not informed about later technological developments - such as wind power plants with a 30-year lifetime or new turbine sizes.

In the annual auction scheme, bidders can adapt their expectations on technological development annually and are able to accommodate information as described above. We assume a more consistent cost degression, making use of McKinsey's (2018) estimations on the developments of technology costs for offshore wind. Positive expectations - such as the development of turbine size or overall plant lifetime - can be reflected in the bids more easily. Furthermore, participation might be enhanced as the policy setting becomes more reliable ${ }^{9}$ - bidders get an idea about the capacity that is reflected in the overall annual budget, the levels of competition, and the costs of their competitors - making the market more transparent. This transforms the auction scheme into a means of tackling the information asymmetry - as it was originally envisaged.

\subsection{Findings from the agent-based simulation}

The first important finding from (re-)simulating the auctions in the agent-based model, is that the bid prices to cover the participant's costs, taking into account the (albeit scarcely) available data on technology costs, are higher in the simulation than those observed empirically - see Figure 3. Maybe this is due to a lack of information on particular technological breakthroughs that will lower costs for offshore wind even more drastically than expected by expert publications. The finding could, however, also prove our initial hypothesis, that some bidders in the auctions see being awarded rather as an option, but not as an obligation, to construct a power plant.

In the following, we show the findings from varying the auction design elements explained earlier, to help understand the empirically observed bidding behaviour. First, we repeat the auction as it took

\footnotetext{
${ }^{9}$ This was, however, not modelled as it would a) make the outcomes too deterministic and b) exacerbate the comparison between the variations, as outcomes could not be attributed unambiguously to the change in the auction design.
} 

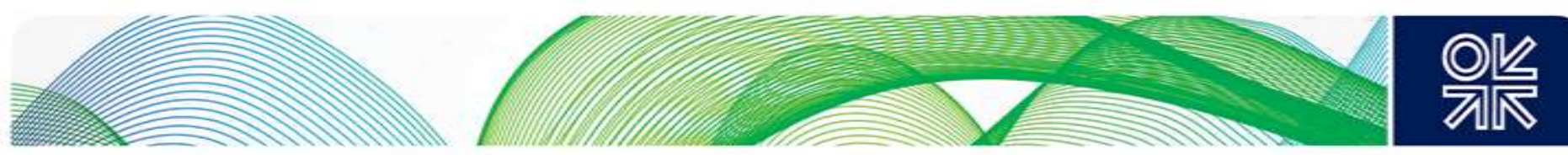

place, but using actual cost data to model the LCOE that offshore bidders would have needed to actually cover their costs in the respective delivery years. Assuming limited information on technology cost developments in 2014 and 2017, we have bidders assume linear cost degression over the five delivery years in the first round, and in the two years of the second round. We also account for the outcomes that were observed empirically and use all this data to construct a realistic bid price range.

We then have bidders participate in an auction scheme where a functioning penalty is in place. This functioning penalty forces bidders to submit their true costs: defaulting because of being awarded support costs that are too low results in a non-viable project and would therefore lead to a financial loss. The findings from modelling are depicted in Figure 3. It can be seen that there is not a lot of difference between the bid prices achieved in the two schemes. However, the case including a penalty shows a smoother development and slightly lower bid prices. This might be due to modelling properties, as we assume that the bid price variation in the case without a penalty ranges around the same level as in the 'penalty case'. As the bid can be higher or lower (see above) and as we assume bidder rationality, this can lead to the overall bid price being slightly higher or lower, depending on the simulation round. The difference is, however, marginal. The important observation here is that a penalty does not increase overall support costs. Furthermore, the simulation shows that on average 5 per cent of capacity per year will not be constructed in the non-penalty case. This seems reasonably low, however, as this is an average value; in an extreme case, as much as $1 \mathrm{GW}$ of offshore wind power could be missing in a certain delivery year. A penalty could thus improve the scheme in terms of deployment and also of planning security for developers (Welisch, 2018).

Figure 3: Simulation of the given auction scheme with and without a penalty (a penalty inducing truthful bidding) and the empirical auction outcomes as comparison

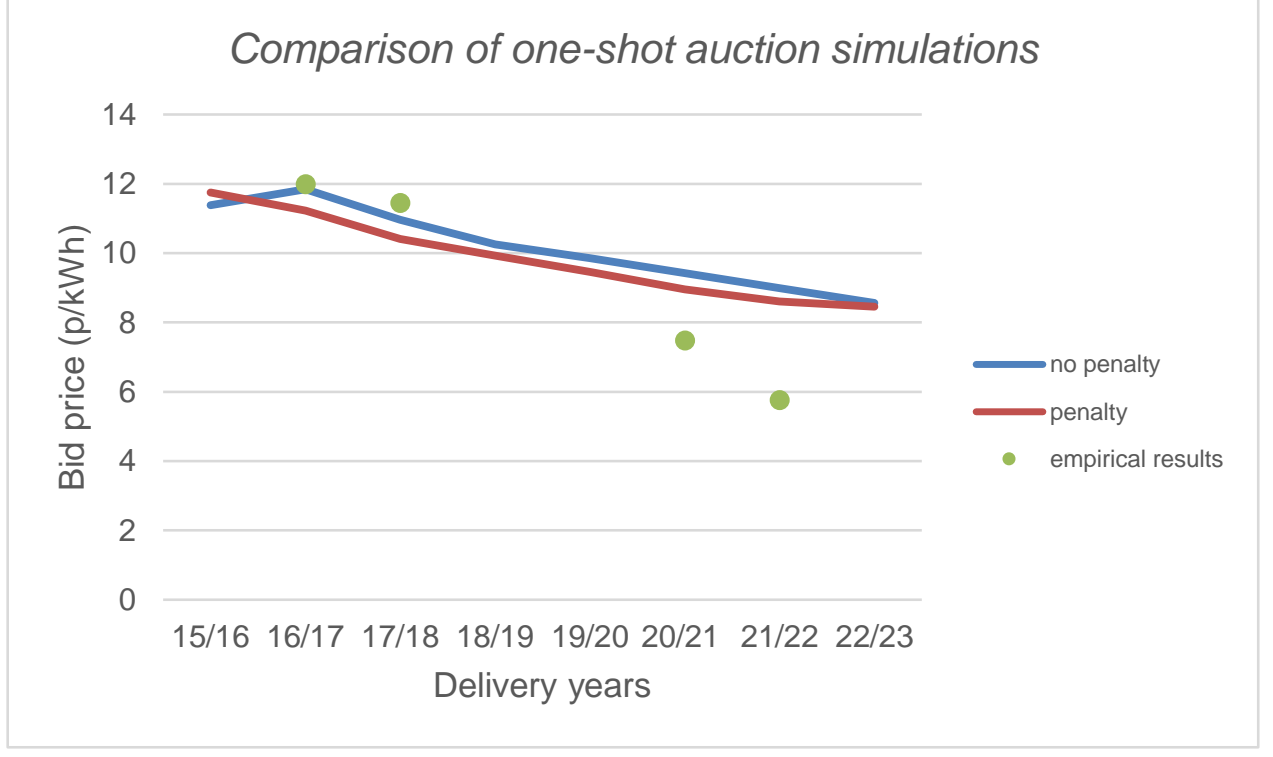

Source: authors

The counterfactual scheme constructed next assumes that instead of having two one-shot auctions we have annual auctions; this enables bidders to generate information on prices from previous rounds (competition level, total capacity auctioned) as well as on technology cost developments. ${ }^{10}$ Figure 4 shows the results. Basically, we can see that the updated information on technology costs becoming

\footnotetext{
${ }^{10}$ For this simulation, we depict results for the alternative scheme with a functioning penalty. Results assuming no penalty show a similar dispersion.
} 

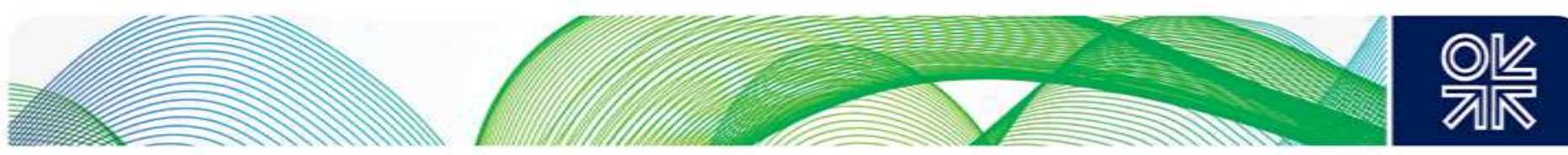

available in each year leads to lower overall bid prices when it can be directly incorporated into participants' bids. One-shot auctions aiming for several delivery years, at a single point in time, leave the auction participants with greater uncertainty concerning support cost needs for later years. Overall, the bid prices in the one-shot auctions are at a slightly higher level compared to a counterfactual scheme of annual auction rounds. This holds even though the extreme price decrease that has been observed empirically in the second one-shot auction has been taken as an input to construct bid prices in the modelling for the one-shot auctions.

Aside from achieving (slightly) lower prices, an annual auction schedule is likely to attract more participants. This is because regular auctions generate information on costs and can improve the value chain, which can induce a more favourable investment climate overall.

\section{Figure 4: Simulation of the given scheme (assuming a functioning penalty and truthful bidding) on an annual vs. a one-shot basis}

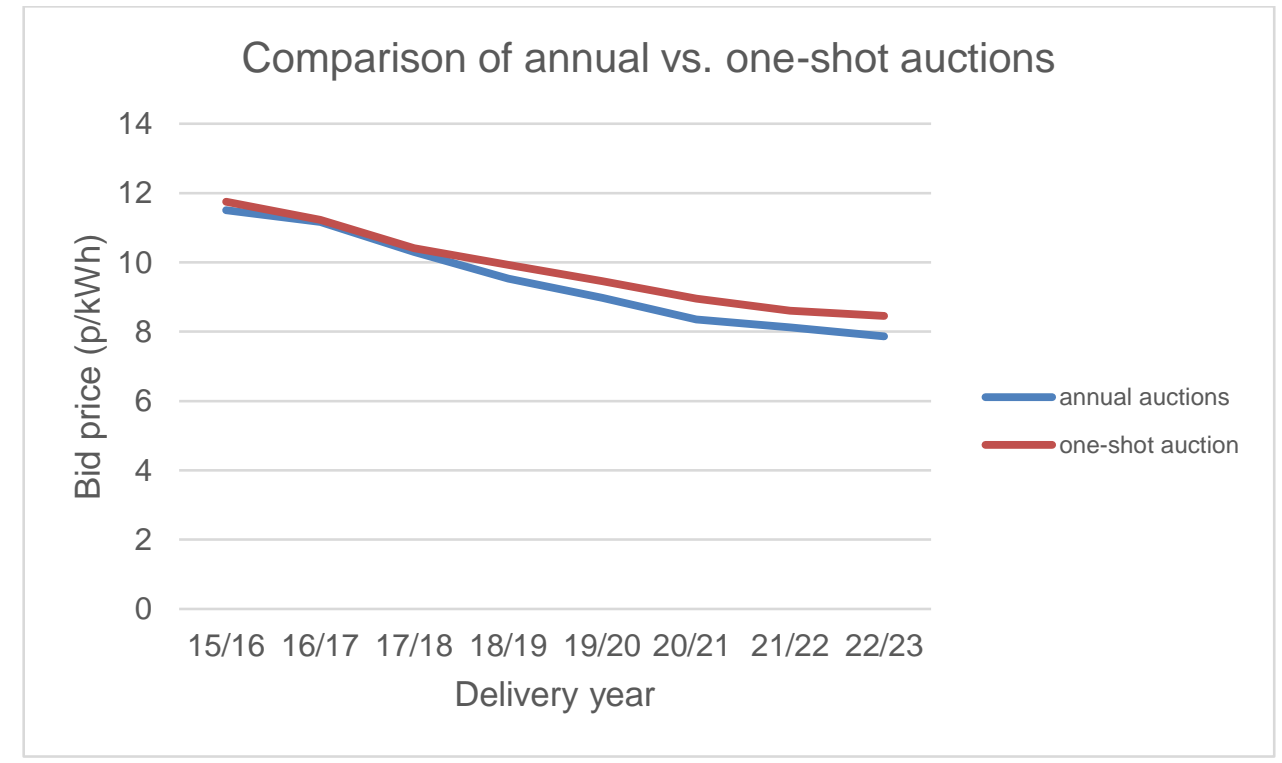

Source: authors

\section{Discussion and conclusions}

This paper investigates auctions for the allocation of offshore wind CfD contracts in the UK. To interpret the outcomes of the CfD scheme, we first account for the investment decision, namely the decision to participate and to what extent. For this, we use a simplified Real Option approach and also analyse the empirical auction outcomes qualitatively, making use of an extensive literature review. The scope of a project submitted as a bid in the auction (including phasing into several partitions) and the bid price are two important determinants that come after the initial decision to participate in the auction. Taking into account the observed behaviour in the auctions, together with theoretical background literature, we demonstrate that the way the CfD auctions are set up gives participants a lot of freedom and might well lead the participation to be a 'real option' rather than a commitment to construct a power plant. Agentbased modelling then provides insights into the impacts that the auction design has on its outcomes. There is also the question of whether the level of bid prices observed empirically was rational (in other words, the amount needed by project developers to cover their costs). Our results show that the modelled bid prices diverge from the empirically observed ones. This could be due to overly optimistic expectations towards technology cost development by actual bidders, where the fact that the CfD auction has no stringent penalty for non-delivery might have had an important impact. 

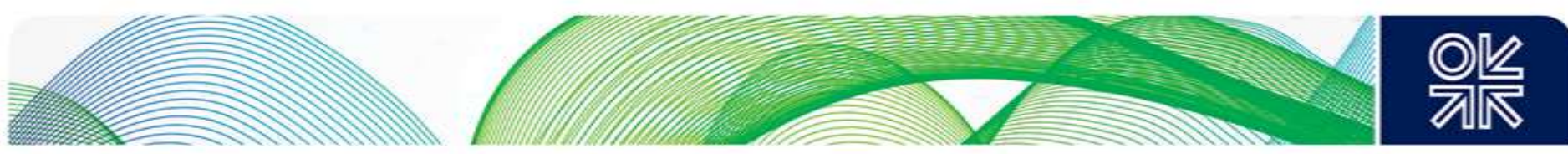

Two variations of the scheme are then modelled to show how changes in the auction design might improve overall participation rates by having the auctions generate more information (with the help of a regular schedule), while greater planning security could be achieved at the same time. Information asymmetry could be tackled by holding annual auctions; bidders could then learn from previous rounds and have better technology cost estimates to submit. The same holds for having a stringent penalty in place. Bidders facing a non-delivery penalty are more likely to reveal their true costs and make an effort to calculate their actual support needs. This design element might deliver more certainty in terms of the capacity actually constructed; however, it needs to be evaluated with respect to its impact on competition. With these two improvements, the auction scheme's goals of both achieving more secure renewable energy sources in the UK and of supporting less mature technologies until they reach market maturity, could be better reached. At the same time, the competitiveness of the UK's offshore wind market would be maintained, strengthening its value chain and providing an attractive investment climate. 

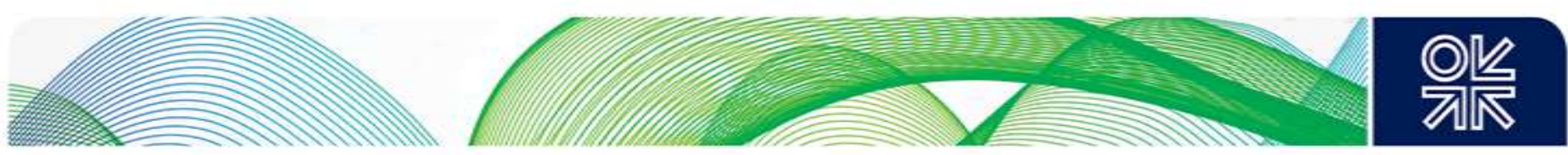

\section{References}

Aurora (2018) "The new economics of offshore wind", Aurora Energy Research Ltd. https://www.auroraer.com/wp-content/uploads/2018/01/The-new-economics-of-offshore-wind.-AuroraEnergy-Research-Report.pdf.

Board, S., 2007. 'Bidding into the Red: A Model of Post-Auction Bankruptcy'. The Journal of Finance 62, 2695-723. https://doi.org/10.1111/j.1540-6261.2007.01290.x.

Boomsma, T.K., Meade, N., Fleten, S.-E., 2012. 'Renewable energy investments under different support schemes: A real options approach'. European Journal of Operational Research 220, 225-37. https://doi.org/10.1016/j.ejor.2012.01.017.

Bowman, E.H., Moskowitz, G.T., 2001. 'Real Options Analysis and Strategic Decision Making'. Organization Science 12, 772-7. https://doi.org/10.1287/orsc.12.6.772.10080.

DECC, 2014. Contract for Difference: Final Allocation Framework for the October 2014 Allocation Round.

Evans, S., 2018. 'Q\&A: What does 'subsidy-free' renewables actually mean?'. Carbon Brief. https://www.carbonbrief.org/what-does-subsidy-free-renewables-actually-mean.

European Commission, 2014. Communication from the Commission - Guidelines on State aid for environmental protection and energy 2014-2020 OJ C 200, 28.6.2014, p. 1-55 (BG, ES, CS, DA, DE, ET, EL, EN, FR, HR, IT, LV, LT, HU, MT, NL, PL, PT, RO, SK, SL, FI, SV), http://eurlex.europa.eu/legal-content/EN/TXT/?uri=CELEX\%3A52014XC0628\%2801\%29

Fitch-Roy, O., Woodman, B., 2016. 'Auctions for Renewable Energy Support in the United Kingdom: Instruments and lessons learnt'. AURES Report D4.1-UK. http://auresproject.eu/publications/auctionsrenewable-energy-support-in-the-united-kingdom-instruments-and-lessons-learnt.

Hailu, A., Rolfe, J., Windle, J., Greiner, R., 2011. Auction Design and Performance: An Agent-Based Simulation with Endogenous Participation, in: Agents and Artificial Intelligence, Communications in Computer and Information Science. Springer Berlin Heidelberg, Berlin, Heidelberg.

https://doi.org/10.1007/978-3-642-19890-8

Heggedal, A.M., Linnerud, K., Fleten, S.-E., 2011. 'Uncertain Policy Decisions and Investment Timing: Evidence from Small Hydropower Plants'. SSRN Electronic Journal.

https://doi.org/10.2139/ssrn.1987701.

IRENA, 2018. 'Renewable Power Generation Costs in 2017'.

https://www.irena.org/publications/2018/Jan/Renewable-power-generation-costs-in-2017.

Klemperer, P., 2004. Auctions: Theory and Practice. SSRN Electronic Journal. https://doi.org/10.2139/ssrn.491563

Krishna, V., 2010. Auction theory, 2nd ed. ed. Academic Press/Elsevier, Burlington, MA.

Lexology (2016) 'UK renewable Contracts for Difference - now only for offshore wind?'. https://www.lexology.com/library/detail.aspx?g=a020e230-09d8-4b51-9dca-a0d92adcc198 [accessed 22 January 2019].

Mahoney, M., 2018. 'Adaptation in the renewables Power Purchase Agreement market'. Energy Spectrum, 627. https://www.cornwall-insight.com/publications/energy-spectrum-and-dailybulletin/energy-spectrum/issue-627/adaptation-in-the-renewables-power-purchase-agreement-market. 

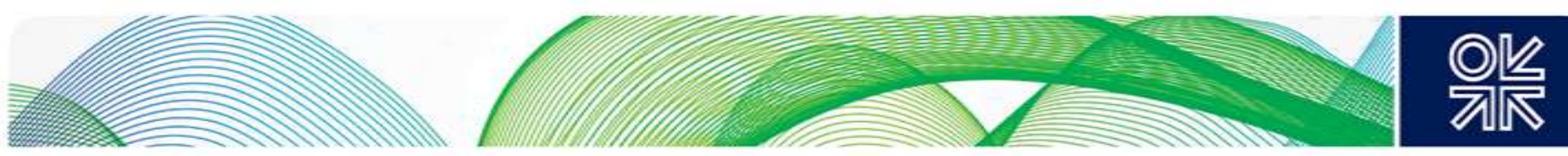

Martínez-Ceseña, E.A., Mutale, J., 2012. 'Wind Power Projects Planning Considering Real Options for the Wind Resource Assessment'. IEEE Transactions on Sustainable Energy 3, 158-66. https://doi.org/10.1109/TSTE.2011.2164102.

Martínez-Ceseña, E.A., Mutale, J., 2011. 'Application of an advanced real options approach for renewable energy generation projects planning'. Renewable and Sustainable Energy Reviews 15, 2087-94. https://doi.org/10.1016/j.rser.2011.01.016.

May, N., Jürgens, I., Neuhoff, K., 2017. 'Renewable energy policy: risk hedging is taking center stage'. DIW Economic Bulletin 7, 389-96,

https://www.diw.de/documents/publikationen/73/diw_01.c.565439.de/diw_econ_bull_2017-39-1.pdf.

McKinsey, 2018. 'Winds of change? Why offshore wind might be the next big thing'. McKinsey Insights. https://www.mckinsey.com/business-functions/sustainability-and-resource-productivity/ourinsights/winds-of-change-why-offshore-wind-might-be-the-next-big-thing.

Milgrom, P., 2004. Putting Auction Theory to Work. Cambridge University Press, Cambridge.

NAO (2017) "Investigation into the 2017 auction for low-carbon electricity generation contracts",

National Audit Office, https://www.nao.org.uk/wp-content/uploads/2018/05/Investigation-into-the-

2017-auction-for-low-carbon-electricity-generation-contracts.pdf.

NERA, 2017. 'Hart am Wind: Einsichten aus der Optionsbewertung zu den Ergebnissen der ersten deutschen Offshore-Wind-Ausschreibung und ihren Auswirkungen'.

http://www.nera.com/content/dam/nera/publications/2017/PUB_Offshore_EMI_German_A4_0417.pdf

Welisch, M., 2018. 'The Importance of Penalties and Pre-qualifications: A Model-based Assessment of the UK Renewables Auction Scheme'. Economics of Energy \& Environmental Policy 7.

https://doi.org/10.5547/2160-5890.7.2.mwel.

WindEurope, 2017. 'The value of hedging: New approaches to managing wind energy resource risk'. dsdvb vc - https://windeurope.org/wp-content/uploads/files/about-wind/reports/WindEurope-SwissRethe-value-of-hedging.pdf. 